\title{
EFFECT OF ZINC IN SEVERE PNEUMONIA IN CHILDREN OF 6 MONTHS TO 5 YEARS IN ALLIED HOSPITAL, FAISALABAD.
}

\footnotetext{
1. MBBS, FCPS (Peadiatric) Assistant Professor Department of Paeds Medicine Children Hospital Faisalabad.

2. MBBS, FCP

Assistant Professor

Department of Paeds Medicine Allied Hospital Faisalabad

3. MBBS, FCPS

Senior Registrar

Department of Paeds Medicine Children Hospital Faisalabad.
}

Correspondence Address:

Dr. Uzma Yasin

Department of Paeds Medicine

Children Hospital Faisalabad.

uzmamannan@gmail.com

Article received on:

12/11/2018

Accepted for publication:

$12 / 03 / 2019$

Received after proof reading:

28/08/2019

\begin{abstract}
Uzma Yasin', Saif Ullah Sheikh², Saher Hameed ${ }^{3}$
ABSTRACT: In Pakistan, pneumonia is very prevalent disease and major cause of death in pediatric age group. Objectives: Our objective is to see the effect of zinc supplementation in severe pneumonia. Study Design: Double blind controlled clinical trial. Setting: Tertiary Care Center of Teaching Hospital. Period: June 2015 to November 2015. Material \& Methods: The study was conducted in tertiary care center of teaching hospital children with age group of "06 month to 05 years" diagnosed as case of severe pneumonia. They were randomly assigned to receive conventional treatment and supplementation with zinc (group A) and conventional treatment (group B) alone. They received $20 \mathrm{mg}$ of elemental zinc from first day of treatment along with conventional treatment. The characteristics like symptoms at admission and variable like age sex were not statistically different in both age groups. Result: The group who received zinc and conventional treatment showed significant decrease in duration of symptoms and duration of hospitalization. Conclusion: This study shows that administration of zinc along with antibiotics can fasten the healing and recovery of pneumonia. We suggest addition of zinc in treatment of pneumonia.
\end{abstract}

Key words: $\quad$ Conventional Treatment, Pneumonia, Zinc Supplementation.

Article Citation: Yasin U, Sheikh S, Hameed S. Effect of zinc in severe pneumonia in children of 6 months to 5 years in Allied Hospital, Faisalabad. Professional Med J 2019; 26(9):1409-1412. DOI: 10.29309/TPMJ/2019.26.09.781

\section{INTRODUCTION}

Pneumonia is most common cause of morbidity and mortality especially in young children. In developing countries it is common cause of mortality among children under 5 years. Pneumonia is accounting for nearly one third of such cases. ${ }^{1}$

According to $\mathrm{WHO}$, approximately 4 million deaths are due to pneumonia. Mostly such death occurred in less than one years of age. ${ }^{2}$ In developing countries micronutrient deficiency like iron and zinc deficiency is common nutritional problem. ${ }^{3}$

Zinc plays various biological functions in human. it plays role in physical development of digestive and immune system. In Zinc deficiency the patients suffer from stunted growth and increased risk of infection like diarrhea and pneumonia. ${ }^{4,5}$ The main cause of zinc deficiency is inadequate intake of zinc in diet. WHO recommends addition of zinc as food supplement in diet.in early infancy zinc deficiency present with acute on chronic diarrhea, malnutrition, psychiatric disorder and behavioral disorder. ${ }^{6}$

The chronic deficiency cause alopecia stunted growth skin lesion and common childhood infection such as pneumonia.

Zinc deficiency can decrease the incidence and duration of disease like pneumonia and diarrhea. ${ }^{7}$

Who recommend zinc supplementation 10mg daily for infant younger than 6 months and $20 \mathrm{mg}$ daily for infant older than 6 months. ${ }^{8}$

The role of zinc is controversial in severe pneumonia some studies recommend zinc supplementation in treatment of pneumonia result in decrease in duration of symptoms and hospitalization. ${ }^{9}$ some studies show no effect of zinc supplementation in treatment. In the present 
study the aim is to justify the role of zinc in severe pneumonia. ${ }^{10}$

\section{MATERIAL AND METHODS}

This study was conducted in 100 patients aged 6 months to 5 years suffering from pneumonia by using double blind controlled clinicaltrial. The permission for study was obtained from research council and ethics committee Punjab medical college Faisalabad from June 2015 to November 2015. The study was conducted after taking informed written consent from children parents. The percipients were randomly assigned b using simple randomization procedure $(1 ; 1)$ to receive zinc (5ml every 12 hourly) along with antibiotic treatment the outcomes were duration of remission of symptoms and duration of hospitalization. The sign and symptoms and diagnostic criteria for pneumonia was taken from nelson text book of pediatritic. ${ }^{7}$ the children of age group 6month to 5years with symptoms of cough, fever, tachypnea, dyspnea, sign of respiratory distress and bilateral crepitation and rhonchi in chest were included in study. The children with family history of atopy, anatomical defect congenital heart disease and malnutrition and other comorbid diseaseswere excluded from study. The duration of symptom and hospitalization was investigated. The data was analyzed by SPSS.

\section{RESULTS}

A total of 100 patients hospitalized from June 2015 to November 2015 were included. In treatment group (group A) 50 patients were assigned to give antibiotics and zinc and in control Group (group B) 50 patients were assigned to antibiotic alone. None of them excluded and leaved the study.

The baseline characteristics were well mentioned in Table-I and there was not statistical difference between in these two group in term of age and sex variable. The ratio of male and female was equal in both groups. The antibiotics include inj. ceftrixone $50-75 \mathrm{mg} \backslash \mathrm{kg}$ in single dose intravenous, inj. ampicillin 100-200mglkglday in three divided doses.

Duration of symptom and hospitalization were taken as standard for efficacy of treatment.
There was significant difference in duration of symptoms and hospitalization in between in two groups. The patients who received zinc and conventional treatment showed shorter period of symptom of pneumonia and their length of stay is also shorter

These results showed that that the zinc can hasten the recovery in pneumonia and shorten the hospital stay.

\begin{tabular}{|c|c|c|c|c|c|}
\hline \multirow{3}{*}{ Age } & & & $\begin{array}{c}\text { Treatment } \\
\text { Group A }\end{array}$ & $\begin{array}{l}\text { Control } \\
\text { Group B }\end{array}$ & P-Value \\
\hline & \multicolumn{2}{|c|}{$\begin{array}{l}06 \text { Months- } \\
02 \text { Years }\end{array}$} & 45 & 45 & \\
\hline & \multicolumn{2}{|c|}{ 02-05 Years } & 05 & 05 & \\
\hline \multirow{2}{*}{ Sex } & \multicolumn{2}{|c|}{ Male } & 25 & 24 & \\
\hline & \multicolumn{2}{|c|}{ Female } & 25 & 26 & \\
\hline \multicolumn{3}{|c|}{ Total Patients } & 50 & 50 & \\
\hline & & & $\begin{array}{c}\text { Treatment } \\
\text { Group A }\end{array}$ & $\begin{array}{l}\text { Control } \\
\text { Group B }\end{array}$ & P-Value \\
\hline \multirow{2}{*}{\multicolumn{2}{|c|}{$\begin{array}{l}\text { Duration of } \\
\text { symptoms } \\
\text { at hospital }\end{array}$}} & $\begin{array}{l}0-5 \\
\text { days }\end{array}$ & $46(92 \%)$ & $35(70 \%)$ & \multirow[b]{2}{*}{0.005} \\
\hline & & $\begin{array}{l}\text { More } \\
\text { than } 5 \\
\text { days }\end{array}$ & 04(8\%) & $15(30 \%)$ & \\
\hline \multirow{2}{*}{\multicolumn{2}{|c|}{$\begin{array}{l}\text { Duration of } \\
\text { hospitali- } \\
\text { zation }\end{array}$}} & $\begin{array}{l}0-5 \\
\text { days }\end{array}$ & $40(80 \%)$ & $30(60 \%)$ & \multirow[b]{2}{*}{0.029} \\
\hline & & $\begin{array}{l}\text { More } \\
\text { than } 5 \\
\text { days }\end{array}$ & $10(20 \%)$ & $20(40 \%)$ & \\
\hline
\end{tabular}

\section{DISCUSSION}

This study aimed to evaluate effect of zinc in pneumonia in hospitalized children 6 month to 5years.

There is no statistically significant difference in term of sex age and severity of disease because of random allocation of patient in both groups. The difference in both groups was addition of zinc in treatment along with antimicrobial therapy.

There is controversial role of zinc in treatment of pneumonia some studies favors addition of zinc in conventional treatment of pneumonia. But other studies showed no effect of zinc in pneumonia. So this present study was aimed to evaluate the effect of zinc in treatment of pneumonia. ${ }^{9,10}$ 
This study showed that zinc can change the clinical course of pneumonia by improving the symptoms and shorter duration of hospitalization.

In one study Brook at al reported that use of zinc in treatment of severe pneumonia leads to improvement in symptoms and shorter duration of treatment. ${ }^{4}$

In 2007 a study conducted in India in children 2 month to 23 month hospitalized due to severe pneumonia. Zinc was given to one group with antibiotic this group showed faster recovery of symptoms. ${ }^{12}$

In 2009 a study conducted on 200 in school going children in university of Mashhad. It was found that number of flu and cold were lower in zinc treated group. ${ }^{11}$

In one study, in India that was conducted on 153 children aged 2 month to 24 month suffer from severe pneumonia hospitalized, one group given antibiotic zinc and vitamin A other group given only antibiotic and vitamin A that study showed faster recovery in group who received zinc with vitamin A and antibiotic. ${ }^{13}$ The UNICEF recommends daily supplementation of zinc $10 \mathrm{mg}$ for younger than 6 month and $20 \mathrm{mg}$ for older than 6 month result in decrease incidence of diarrhea and pneumonia.

\section{CONCLUSION}

This study shows that zinc can improve outcome and fasten the recovery in pneumonia it also decrease the incidence of multiple antibiotic resistance caused by multiple antibiotic therapies. So it is recommended that zinc should be added in treatment of lower respiratory tract infection on arrival of patient in hospital .we also recommend further research work in this field.

\section{Copyright@ 12 Mar, 2019.}

\section{REFERENCES}

1. B.G. William, E. Gouws and C. Boschi-Pinto, "Estimates of worldwide distribution of child deaths from acute respiratory tract infection, Lencet infectious disease", 2002, 2(1):25-32.
2. N.J. Faghihi, P.M. Hashem and H. HRahimi, "Pneumonia in children: Is it related to Zinc deficiency, Journal of research in medical sciences, 2001, 6(3):219-223.

3. M.O.N.I.R. Ramizani, F.A.Z.L.O.L.A. Ahmadi, and S.Kermanshahi, "The effect of desire care plan on the duration and rate of pneumonia in infant in children medical centrein tahran, koomesh", 2006, 7(1),27-34.

4. W. A. Brooks, M. Yunus, M. Santosham et al., "Zinc for severe pneumonia in very young children: doubleblind placebo-controlled trial," The Lancet, 2004, 363(9422):1683-88.

5. F. Emamghorashi and T. Heidari, "Iron status of babies born to iron-deficient anaemic mothers in an Iranian hospital," Eastern Mediterranean Health Journal, 2004, 10(6): 808-14.

6. N. M. Díaz-Gómez, E. Doménech, F. Barroso, S. Castells, C. Cortabarria, and A. Jiménez, "The effect of zinc supplementation on linear growth, body composition, and growth factors in preterm infants," Pediatrics, 2003, 111(5): 1002-9.

7. Abbott M, Vlasses C. Nelson Textbook of Pediatrics. Jama: The Journal of the American Medical Association. 2011 Dec 1;306(21):2387-8.

8. M. Y. Yakoob, E. Theodoratou, A. Jabeen et al., "Preventive zinc supplementation in developing countries: impact on mortality and morbidity due to diarrhea, pneumonia and malaria," BMC Public Health, 2001, 11(3):22-23.

9. Iqbal I, Mahmood S, Tariq A. "Effect of oral zinc supplementation on duration of illness and mortality in children in conventional treatment for pneumonia. Nishtar Med J., 2010, 2(2):51-5.

10. Valentiner-Branth $P$, Shrestha PS, Chandyo RK, Mathisen M, Basnet S, Bhandari N, et al. "A randomized controlled trial of the effect of zinc as adjuvant therapy in children 2-35 mo of age with severe or nonsevere pneumonia in Bhaktapur, Nepal. Am J ClinNutr, 2010, $91(6): 1667-74$.

11. R. Vakili, M. Vahedian, G.-H. Khodaei, and M. Mahmoudi, "Effects of zinc supplementation in occurrence and duration of common cold in school aged children during cold season: A double-blind placebocontrolled Trial," Iranian Journal of Pediatrics, 2009, 19(4): 376-380, 2009.

12. C. L. Coles, A. Bose, P. D. Moses et al., "Infectious etiology modifies the treatment effect of zinc in severe pneumonia," The American Journal of Clinical Nutrition, 2007, 86(2):397-403. 
13. D. Mahalanabis, M. Lahiri, D. Paul et al., "Randomized, double-blind, placebo-controlled clinical trial of the efficacy of treatment with zinc or vitamin $A$ in infants and young children with severe acute lower respiratory infection," The American Journal of Clinical Nutrition, 2004, 79(3): 430-436.

\begin{tabular}{|c|l|l|l|}
\hline \multicolumn{3}{|c|}{ AUTHORSHIP AND CONTRIBUTION DECLARATION } \\
\hline Sr. \# & \multicolumn{1}{|c|}{ Author-s Full Name } & \multicolumn{1}{|c|}{ Contribution to the paper } & Author=s Signature \\
\hline 1 & Uzma Yasin & Author & \\
\hline 2 & Saif Ullah Sheikh & Co-author & \\
\hline 3 & Saher Hameed & Co-author & \\
\hline
\end{tabular}

